\title{
Sustainable land use for mitigation
}

\author{
The latest IPCC report highlights that a change in diets for richer nations, and smarter land use, could ensure food \\ security and mitigation of potential climate impacts.
}

and surface processes - agriculture, forestry and other land use - account for $28 \%$ of anthropogenic emissions. However, natural land processes absorb about a third of the emissions from fossil fuel burning and energy production. Although only $1 \%$ of the world's land surface is taken up by infrastructure, according to the latest IPCC report (https://www.ipcc.ch/report/srccl/), there have been great changes to the surface throughout human history, with $12-14 \%$ of ice-free land now being used for cropping, $37 \%$ being grasslands that are used for grazing and other purposes, and $22 \%$ being managed or planted forests. This leaves only about $28 \%$ of ice-free land untouched or minimally touched by humans, highlighting that there are many areas ripe for better management and use. Such improvements could lessen, but not solve, the need for climate mitigation.

Food security and diet feature heavily in the new report, as it is essential for survival that regional food supply is maintained. Productivity will need to be maintained or increased in a changing climate, but improved systems are needed to reduce the losses from production and waste that account for about a third of food produced. Food has already been in the spotlight this year, with the release in January of the EAT-Lancet commission $^{1}$, which focused on diet, health and planetary boundaries (as discussed in our March editorial ${ }^{2}$ ) and found that a change in diet would benefit both human and planetary health. That message is reinforced by the IPCC report. Dietary changes, particularly in the richer nations which have high levels of meat consumption, would free up land for other uses, as well as reducing emissions by up to $8 \mathrm{Gt} \mathrm{CO}_{2}$-equivalent per year, relative to business as usual.

Deforestation, degradation and desertification all threaten land carbon sinks. Approximately 500 million people live in areas at risk of desertification, and climate change exacerbates the risks in these areas as well as drylands.

A known positive of increased atmospheric $\mathrm{CO}_{2}$ concentrations is increased plant productivity $-\mathrm{CO}_{2}$ fertilization. But this fertilization may be limited by nutrient availability, according to two recent studies. Katrin Fleischer and colleagues report in Nature Geoscience ${ }^{3}$ that terrestrial ecosystem model results show that phosphorus availability will affect the Amazon forest's

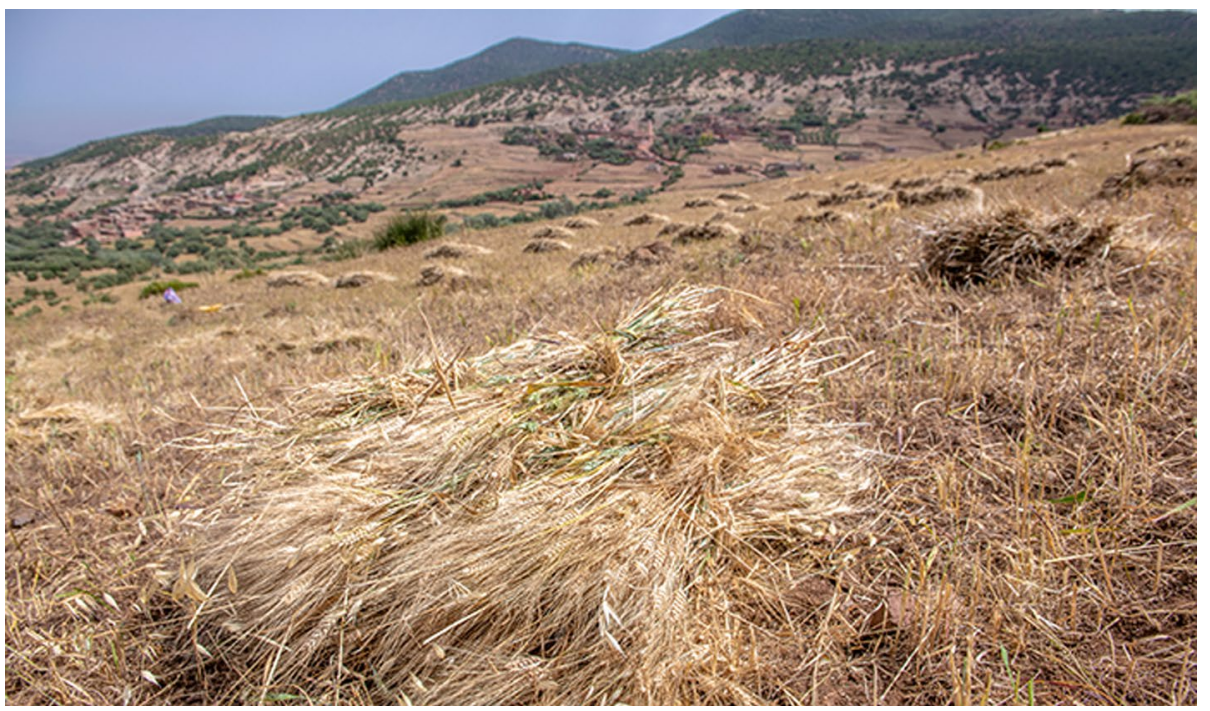

Credit: Edwin Remsberg/The Image Bank/Getty

response to higher atmospheric $\mathrm{CO}_{2}$. This is echoed in a paper in this issue by César Terrer and co-authors, who use aboveground biomass observations collected from 205 studies to show that the availability of the nutrients nitrogen and phosphorus drives the magnitude of the $\mathrm{CO}_{2}$ effect for most vegetation globally. The authors show that strength of the fertilization effect is primarily driven by nitrogen for around 65\% of global vegetation, whereas phosphorus is key for about $25 \%$. Despite potential nutrient limitation, $\mathrm{CO}_{2}$ fertilization will still result in increased biomass and a drawdown of carbon of around $12 \%$, equivalent to about 59 GtC by 2100 .

Water availability and stress will also affect productivity. The persistence of extreme summer weather - heatwaves, heavy rainfall or hot-dry periods - is projected to increase globally, according to Peter Pfleiderer and colleagues, ${ }^{4}$, writing in Nature Climate Change. Regional variation means that eastern North America could see a $20 \%$ increase in hot-dry periods that exceed 2 weeks, which could have serious implications for crop productivity.

The IPCC Special Report on Climate Change and Land, which had its Summary for Policymakers approved by the world's governments, allowing the report's release on Thursday 8 August, is the second of the three special reports being produced during the sixth assessment cycle. The Special Report on Global Warming of $1.5^{\circ} \mathrm{C}$, released in November 2018, was the first and highlighted the benefits of limiting warming to less than $1.5^{\circ} \mathrm{C}$ above pre-industrial values. Although the Summary for Policymakers was approved, allowing the report's release, in December 2018 and again at the recent Bonn meeting, the United States of America, Russia, Saudi Arabia and Kuwait (major fossil-fuelproducing nations) declined the inclusion of emissions targets from the study into the UN process (go.nature.com/2zhXOfe).

Creative thinking and technology advances could offer solutions, combined with individual efforts, supported by government policies, to move mitigation efforts forward. It will be interesting to see how the UN process plays out with inclusion of the findings from this latest special report, as well as the $1.5^{\circ} \mathrm{C}$ report and the forthcoming report on Ocean and Cryosphere in a Changing Climate (September 2019), as the science must inform future policy.

Published online: 28 August 2019 https://doi.org/10.1038/s41558-019-0575-9

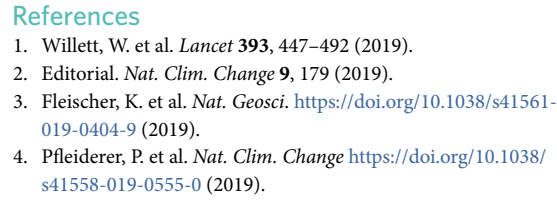

